(3.0\%), business professionals $(2.9 \%)$ and cultivators $(2.8 \%)$. Low back $(23.3 \%)$, knee $(12.7 \%)$ and shoulder $(6.1 \%)$ were the most frequent site of complaint. Non specific low back pain $(12.7 \%)$ and knee osteoarthritis $(7.3 \%)$ were the two top ranking disorders. The prevalence of rheumatoid arthritis was $1.6 \%$ and spondyloarthritis $1.2 \% .5 .5 \%$ of the respondents had disability from rheumatic problems. Conclusions: About one third of the Bangladeshi adults suffer from musculoskeletal pain at a given point of time. There are residence and gender variation in the prevalence rates. Low back and knee pain were the principal sites of complaints. Disclosure of Interest: None declared

DOI: 10.1136/annrheumdis-2017-eular.2562

\section{SAT0714 INCREASED RISK OF OPPORTUNISTIC INFECTION IN THE EARLY STAGE OF RHEUMATOID ARTHRITIS}

H. Kim ${ }^{1}$, S.-K. Cho ${ }^{1,2}$, M.J. Kim ${ }^{1}$, G.Y. Ahn ${ }^{1}$, H.H. Kwon ${ }^{1}$, D. Kim ${ }^{1}$, J. Lee ${ }^{2}$, S.-C. Bae ${ }^{1,2}$, Y.-K. Sung ${ }^{1} .{ }^{1}$ Department of Rheumatology, Hanyang University Hospital for Rheumatic Diseases; ${ }^{2}$ Clinical Research Center for Rheumatoid Arthritis (CRCRA), Seoul, Korea, Republic Of

Background: The increased risk of opportunistic infections (OIs) in rheumatoid arthritis (RA) patients who started biologic disease modifying anti-rheumatic drugs (DMARDs) has been well known. However, it has not been studied regarding the increased risk of Ols in the early stage of RA.

Objectives: To study the increased risk of incidence rate (IR) of Ols in early RA patients compared with established RA patients, and to evaluate the risk factors for developing the Ols in the early stage of RA.

Methods: Retrospective cohorts of early and established RA patients were conducted independently using the Korean National Healthcare claims database. Early RA patients $(n=14,081)$ were identified in 2010 having disease free period for 1 year before index date, and receiving continuous treatment for over three years. Established RA patients $(n=226,838)$ were recruited between 2010 and 2012 with using the ICD10 code of RA and any DMARD use. Follow-up started on the index date and ended on the data of the development of Ols, at 12 months, or at the time of death. The incidence rates of Ols were compared between two groups by calculating incidence rates ratio (IRR) and standardized incidence ratio (SIR) for overall or each Ols. The multivariable regression model was used to evaluate the risk factors for Ols in the early stage of RA.

\section{Table 1}

\begin{tabular}{|c|c|c|c|c|c|c|}
\hline \multirow[t]{2}{*}{$\begin{array}{l}\text { Type of opportunistic } \\
\text { infection }\end{array}$} & \multicolumn{2}{|c|}{$\begin{array}{c}\text { Established RA } \\
\mathrm{N}=226,838\end{array}$} & \multicolumn{2}{|c|}{$\begin{array}{l}\text { Early RA } \\
\mathrm{N}=14,081\end{array}$} & \multicolumn{2}{|c|}{$\begin{array}{c}\text { SIR comparing early RA } \\
\text { patients with establishec } \\
\text { RA patients }\end{array}$} \\
\hline & $\mathrm{IR} / 100 \mathrm{PY}$ & $95 \% \mathrm{Cl}$ & $\mathrm{RR} / 100 \mathrm{PY}$ & $95 \% \mathrm{Cl}$ & SIR & $95 \% \mathrm{Cl}$ \\
\hline Total & 3.67 & $3.59-3.74$ & 3.81 & $3.52-4.11$ & 1.14 & $1.05-1.23$ \\
\hline Tuberculosis & 0.71 & $0.67-0.75$ & 0.70 & $0.54-0.87$ & 1.06 & $0.82-1.33$ \\
\hline Herpes zoster & 2.79 & $2.72-2.85$ & 2.89 & $2.64-3.13$ & 1.12 & $1.03-1.22$ \\
\hline Cytomegalovirus & 0.02 & $0.02-0.03$ & 0.03 & $0.00-0.06$ & 0.98 & $0.20-2.86$ \\
\hline Epstein-Barr virus & 0.01 & $0.00-0.01$ & 0.04 & $0.00-0.07$ & 3.54 & $0.96-9.06$ \\
\hline \multirow{2}{*}{\multicolumn{7}{|c|}{ Pneumocystis jiroveci }} \\
\hline & 0.01 & $0.01-0.02$ & 0.02 & $-0.01-0.04$ & 1.20 & $0.15-4.34$ \\
\hline Candidiasis & 0.10 & $0.08-0.11$ & 0.11 & $0.07-0.16$ & 2.40 & $1.55-3.54$ \\
\hline Aspergillosis & 0.02 & $0.02-0.03$ & 0.02 & $0.00-0.05$ & 0.84 & $0.17-2.47$ \\
\hline Cryptococcosis & 0.01 & $0.00-0.01$ & 0.01 & $-0.01-0.02$ & 1.15 & $0.03-6.39$ \\
\hline
\end{tabular}

$\mathrm{RA}$ = rheumatoid arthritis, $\mathrm{SIR}$ = standardized incidence ratio, $\mathrm{PY}=$ person year, $\mathrm{N}=$ number, IR = incidence rate, $\mathrm{Cl}=$ confidence interval .

Results: The IRs of overall OI in early and established RA patients were 3.81 (95\% Cl 3.52-4.11)/100PY and 3.67 (95\% Cl, 3.59-3.74)/100PY, respectively. The SIR for overall Ols in early RA patients was $1.14(95 \% \mathrm{Cl}, 1.05-1.23)$. The herpes zoster (SIR 1.12, 95\% Cl 1.03-1.22) and candidiasis (SIR 2.40; $95 \% \mathrm{Cl} 1.55-3.54$ ) were commonly affected in the early stage of RA patients. Older age more than 50 years old [ $50<$ age $\leq 60$ (OR 1.74, 95\% Cl 1.30-2.33), $60<$ age $\leq 70$ (OR $1.85,95 \% \mathrm{Cl} 1.36-2.52$ ), 70 <age (OR 1.89, 95\% Cl 1.342.68 )], more comorbidities [one comorbidities (OR 1.53, 95\% Cl 1.24-1.89), $\geq 2$ of comorbidities (OR 1.84, 95\% Cl 1.47-2.29)], and corticosteroid $\geq 5 \mathrm{mg}$ per day (OR 1.38, 95\% Cl 1.13-1.69) were associated with increased risk of Ols in the early stage of RA patients.

Conclusions: The incidence of Ols is increased in early stage of RA patients compared with established RA patients. Old age, comorbidities, high corticosteroid dose were related with the development of Ol. Physicians should be aware of the possible occurrence of Ols in early stage of RA treatment.

Disclosure of Interest: None declared

DOI: 10.1136/annrheumdis-2017-eular.4882

\section{SAT0715 CLINICAL SIGNIFICANCE OF FIBROMYALGIA SYNDROME IN DIFFERENT RHEUMATIC DISEASES: RELATION TO DISEASE ACTIVITY AND QUALITY OF LIFE}

T.A. Gheita, S.M. El-Rabbat, N.K. Mahmoud. Rheumatology and Clinical Immunology Department, Faculty of Medicine - Kasr Al-Ainy School of Medicine Cairo University, Cairo, Egypt

Background: In clinical practice, the co-expression of fibromyalgia syndrome (FMS) and a rheumatologic disease deserves special attention as FMS may go unrecognized especially when it develops after the disease or more commonly when it is misdiagnosed as an autoimmune disorder.

Objectives: The aim of the present work was to compare the frequency of FMS in rheumatoid arthritis (RA), systemic lupus erythematosus (SLE), systemic sclerosis (SSc) and Behçets disease (BD) patients and to study the relation of FMS to the clinical manifestations, laboratory features, disease activity and/or damage as well as the quality of life (QoL).

Methods: One hundred and sixty patients (50 RA, 50 SLE, 30 SSc and 30 BD) consequently recruited from those attending the Rheumatology outpatient clinic and department, Faculty of Medicine, Cairo University Hospital. and 141 age and sex matched corresponding healthy controls were included. Disease activity was assessed using Disease Activity Score in 28 joints (DAS28) for RA, SLE Disease Activity index (SLEDAI), modified Rodnan skin score for SSc and BD Current Activity Form (BDCAF). The Systemic Lupus International Collaborating Clinics (SLICC)/ACR damage index was assessed in SLE patients. The quality of life (QoL) was also recorded. Severity in FMS cases was estimated using the revised Fibromyalgia Impact Questionnaire (FIQ) score.

Results: In the RA, SLE, SSc and BD patients, FMS was found in $14 \%, 18 \%$, $6.67 \%$ and $3.33 \%$ respectively compared to $2.1 \%, 3 \%, 3.3 \%$ and $0 \%$ in their corresponding controls. In RA patients, DAS28 was significantly higher in those with FMS (5.5 \pm 0.9$)$ compared to those without $(4.3 \pm 1.3)(\mathrm{p}=0.009)$; significantly correlated with both Widespread Pain Index (WPI) $(p=0.011)$ and Symptom Severity (SS) scale $(p=0.012)$ and the QoL scale in those with FMS was significantly worse $(62.3 \pm 7.9)$ compared to those without $(71.7 \pm 14.4)(p=0.023)$. In SLE patients, The WPI and SS both significantly correlated with the presence of thrombosis $(r=0.28$, $p=0.049$ and $r=0.43, p=0.002$ respectively). The $S S$ scale tended to correlate with the SLEDAI $(r=0.28, p=0.05)$. In BD patients, BDCAF and WPI significantly correlated $(p=0.03)$. On comparing the WPI among the rheumatic diseases patients, the mean was significantly higher in the SLE patients $(2.3 \pm 3.2)$ compared to that in the RA (1.96 \pm 2.6$)$, SSc $(1.9 \pm 2.2)$ and $B D(0.7 \pm 1.1)$ patients $(\mathrm{p}=0.047)$. Conclusions: Fibromyalgia syndrome is more frequent in rheumatic diseases. The significance of this study is boosted by the fact that it was among the first to investigate the prevalence of FMS in patients with SSc. Also, adds to the limited insights on the relation of FMS to BD. It is novel to present the relative prevalence of FMS in different Egyptian rheumatic diseases patients and to throw light on the association with disease activity in RA and BD as well as thrombosis in SLE. The impact of FMS on the QoL in RA patients requires special attention.

Disclosure of Interest: None declared

DOI: 10.1136/annrheumdis-2017-eular.2207

\section{SAT0716 A FIRST TIME HOSPITAL ADMISSION FOR COMORBID CONDITIONS IN PATIENTS WITH SYSTEMIC LUPUS ERYTHEMATOSUS IS MORE FREQUENTLY DUE TO CARDIOVASCULAR AND RENAL COMPLICATIONS THAN IN CONTROLS AND SUBSEQUENTLY INCREASES THE RISK FOR DEATH}

W.D. Raymond ${ }^{1}$, D. Preen ${ }^{2}$, C. Inderjeeth ${ }^{1,3}$, H. Keen ${ }^{4,5}$, J. Nossent ${ }^{1,6},{ }^{1}$ School of Medicine \& Pharmacology; ${ }^{2}$ School of Population Health, University of Western Australia; ${ }^{3}$ Rehabilitation and Aged Care, Sir Charles Gairdner Hospital; ${ }^{4}$ Rheumatology, Fiona Stanley Hospital; ${ }^{5}$ School of Medicine, Murdoch University; ${ }^{6}$ Rheumatology, Sir Charles Gairdner Hospital, Perth, Australia

Background: Systemic Lupus Erythematosus (SLE) is a chronic autoimmune disease that runs an unpredictable disease course.

Objectives: We aimed to understand the characteristics and outcomes of incident hospitalisation for conditions other than the underlying disease in SLE patients. Methods: Using whole-population data linkage of hospital admissions and death records in Western Australia (WA) WA between 1980 and 2015, we performed a retrospective analysis for patients where SLE (ICD-9-CM 695.4, 710.0 and ICD-10-AM L93.0 \& M32) was a co-existing discharge diagnosis. All SLE patients were age- and gender-matched with hospital controls free of rheumatic disease. We investigated the rate and characteristics of the index hospitalisation for comorbidity and the risk of subsequent death by Kaplan-Meier survival and Cox regression.

Table 1: Patient Characteristics (at index hospitalisation) and study outcomes.

\begin{tabular}{|c|c|c|c|}
\hline & $\begin{array}{l}\text { Lupus was secondary } \\
\text { to the Admitting } \\
\text { Diagaosis }\end{array}$ & Matcled Controls & 22 or t-test \\
\hline & MocT or $\mathrm{a}(\%)$ & Moct or $\mathrm{b}(\%)$ & (p-value) \\
\hline Age & $54.31=18.76$ & $54.32 \pm 22.13$ & 0.120 \\
\hline Female & $1911(\$ 2.3 \%)$ & $1755(82.8 \%)$ & 0.210 \\
\hline Indigenous Status. & $82(3.5 \%)$ & $26(1.290)$ & $<0.001$ \\
\hline Length of Stay (days) & $5(\mathrm{IQR} 2,11)$ & $2(\operatorname{tQR} 1,5)$ & $<0.001$ \\
\hline Privately Insured & $438(35.49 \%)$ & $469(48.8 \%)$ & $<0.001$ \\
\hline Diaguosed with an Ischaemic Heart Disorder & $184(7.9 \%)$ & $73(3.4 \%)$ & $<0.001$ \\
\hline Diaguosed with a Cerebral Ischaemic Disorder & $33(1.4 \%)$ & $18(0.8 \%)$ & 0.074 \\
\hline Diagnosed with a $\mathrm{H}_{\text {yperteasion }}$ Disorder & $348(15.09 \%)$ & $136(6.4 \%)$ & $<0.001$ \\
\hline Diagnosed with an Atherosclerotic Disorder & $158(6.8 \% 6)$ & $19(0.99)$ & $<0,001$ \\
\hline Diaguosed with a Kideey Disorder & $295(12.7 \%)$ & $39(1.8 \%)$ & $<0.001$ \\
\hline Diagnosed with a Thrombotic Disorder & $34(2.3 \%)$ & $4(0.2 \%)$ & $<0.001$ \\
\hline Patieat died during the bospital admission & $87(3.7 \%)$ & $40(1.9 \%)$ & $<0.001$ \\
\hline
\end{tabular}

